\title{
DIREITOS DE PERSONALIDADE DO TRABALHADOR E LIMITES DO PODER DIRETIVO DO EMPREGADOR: O BALANCING TEST COMO TÉCNICA DE PONDERAÇÃO
}

\author{
Rodrigo Garcia Schwarz* \\ Rosane Machado Carneiro**
}

Resumo:

O presente artigo trata de verificar como harmonizar o poder diretivo do empregador e os direitos fundamentais do trabalhador, especialmente os de personalidade, diante de situações de aparente colisão na execução do contrato de trabalho a partir do princípio da proporcionalidade, com a utilização, como instrumento de ativação da ponderação, da técnica do balancing test, que permite identificar, no caso concreto, diante da aparente colisão, qual desses direitos deve ser resguardado de forma mais contundente, e como, maximizando-o, em detrimento do outro, que será, para aquele caso específico, minimizado ou relativizado. O procedimento investigativo é descritivo-explicativo do tipo documental-bibliográfico.

Palavras-chave: balancing test; direitos de personalidade do trabalhador; direitos fundamentais; poder diretivo do empregador; relações de trabalho

\section{EMPLOYEE'S PERSONALITY RIGHTS AND LIMITS OF THE EMPLOYER'S} DIRECTIVE POWER: THE BALANCING TEST AS WEIGHTING TECHNIQUE

\section{Abstract:}

This article aims to verify how to harmonize the employer's directive power and the employee's personality rights in situations of apparent collision in the execution of the work contract from the principle of proportionality, with the use, as instrument, of balancing test,

\footnotetext{
* Professor Permanente do PPGD do Centro Universitário FIEO - UNIFIEO, Doutor em Direito e em História Social (Pontifícia Universidade Católica de São Paulo), Líder do Grupo de Pesquisa (DGP-CNPq) Dimensão Material e Efetivação Jurisdicional dos Direitos Econômicos, Sociais e Culturais: Relações de Trabalho e Seguridade Social. E-mail: rgschwarz@gmail.com.

** Mestre em Direito pela Universidade do Oeste de Santa Catarina - UNOESC, Membro do Grupo de Pesquisa (DGP-CNPq) Dimensão Material e Efetivação Jurisdicional dos Direitos Econômicos, Sociais e Culturais: Relações de Trabalho e Seguridade Social.E-mail: advrosanemachado@ gmail.com.
} 
which allows identifying, in the concrete case, before the apparent collision, which of these rights should be protected more forcefully, and how, maximizing it, to the detriment of the other that will be, for that specific case, minimized or relativized. The investigative procedure, of documentary and bibliographic type, is descriptive and explanatory.

\section{Keywords:}

balancing test; labour relations; employee's personality rights; fundamental rights; employer's directive power

\section{CONSIDERAÇÕES INICIAIS}

A preservação da dignidade demanda respeito à condição de ser humano, de per si. No âmbito das relações de trabalho, a subordinação jurídica e a dependência do trabalhador - e o correspondente poder diretivo do empregador - não escusam qualquer dano à dignidade do trabalhador.

$\mathrm{O}$ contrato de emprego diferencia-se pelos pressupostos estabelecidos no artigo $3^{\circ}$ da CLT, consubstanciando relação pessoal e subordinada, em relação ao trabalhador que presta seus serviços assalariados ao empregador, que tem, em contrapartida, o poder de dirigir tal prestação - o poder diretivo (DELGADO, 2014).

O poder diretivo do empregador, contudo, não é absolutamente potestativo, tampouco pode ser exercido de forma ilimitada; antes, está efetivamente adstrito aos limites do contrato, bilateral, e à dignidade do trabalhador, alçada à condição de garantia constitucional (SCHWARZ, 2011).

O contrato de trabalho, portanto, na sua execução, inclusive quanto às expressões do poder diretivo dele decorrentes, deve preservar os direitos de personalidade do trabalhador (NASCIMENTO, 2013), atentando para a sua hipossuficiência estrutural, não só econômica, mas delineada pela dependência jurídica - a subordinação - frente ao empregador (MERINO et al., 2015).

Portanto, embora o trabalhador, por força do contrato de trabalho, se coloque em uma situação funcional de sujeição (CORDEIRO, 1994), o poder diretivo do empregador não pode atentar contra a dignidade da pessoa do trabalhador, mantida a sua condição humana, de pessoa e, portanto, de sujeito de direitos fundamentais na execução de suas atividades, ainda que sob subordinação. O respeito aos direitos fundamentais da pessoa, assim, erige, no âmbito da 
relação de trabalho, importante limite aos poderes do empregador e, ao mesmo tempo, garantia de exercício de direitos fundamentais, inclusive daqueles relacionados à personalidade.

Nesse sentido, o escopo do presente artigo é verificar como a harmonização entre o poder diretivo do empregador e os direitos fundamentais do trabalhador, especialmente os direitos de personalidade, como pessoa, diante de situações de aparente colisão, por força do contrato de trabalho, pode ser mediada a partir do princípio da proporcionalidade, com o recurso, como instrumento de ativação da ponderação, à técnica do balancing test, que permite identificar, no caso concreto, diante da aparente colisão, qual desses direitos deve ser resguardado de forma mais contundente, e como, maximizando-o, em detrimento do outro que vai ser, para aquele caso específico, minimizado ou relativizado.

A questão a ser debatida, em síntese, é como instrumentalizar a compatibilização do direito do empregador, de dirigir e fiscalizar a prestação pessoal de serviços, inerente ao contrato de trabalho, com a preservação da intimidade do empregado, direito de personalidade de que não se priva aquele que aceita prestar serviços de forma subordinada.

\section{A EFICÁCIA DOS DIREITOS FUNDAMENTAIS NO DIREITO DO TRABALHO}

A positivação de direitos fundamentais passou por diversas transformações ao longo da história, bem como suas inerentes ampliações, tanto no que diz com o seu conteúdo, quanto no que concerne à sua titularidade, eficácia e efetivação, o que se estendeu também para as relações privadas, como aquelas pertinentes ao ambiente de trabalho.

Se pelo contrato de trabalho o empregador tem o poder diretivo, impondo-se a sua autoridade, por outro o trabalhador não deixa de, na execução da relação de emprego, manter os seus direitos de personalidade.

Os direitos fundamentais surgem como instrumentos de defesa dos indivíduos contra os excessos do Estado, ou seja, como freios e anteparos à interferência estatal ilegítima ou abusiva nas esferas da liberdade ou da autonomia individual. São, pois direitos de defesa oponíveis ao Estado e limitadores da sua atuação. No entanto, como destaca Luño $(1989$, p. 6) “a passagem do Estado liberal para o Estado Social de Direito permitiu (...) a extensão da incidência dos direitos fundamentais a todos os setores do ordenamento jurídico e, portanto, também ao campo das relações entre particulares". Essa ampliação dos direitos fundamentais à esfera privada ou em relação a terceiros é conhecida, na doutrina alemã, como Drittwiirkung der Grudrechte. 
Dessa forma, as transformações sofridas pelo Estado e pela sociedade e a evolução dos direitos fundamentais possibilitaram que estes fossem também aplicáveis às relações privadas, entre particulares, horizontalmente, especialmente para eliminar ou reduzir as desigualdades entre as pessoas, com o escopo de promoção de igualdade material, e não meramente formal, até porque os direitos fundamentais alicerçam-se no princípio da dignidade da pessoa.

A dignidade social da pessoa humana está intrinsecamente ligada à generalização do Direito do Trabalho. Nessa esteira, afirma-se que apenas através do trabalho em condições compatíveis com tal dignidade, em que se asseguram a segurança e o respeito ao ser humano, a pessoa torna-se capaz de se afirmar e de se realizar plenamente enquanto ser social.

Para a concretização da dignidade da pessoa humana, é indispensável a valorização do trabalho, por meio da efetivação das normas trabalhistas, pois é o labor a peça fundamental de afirmação individual e social do ser humano. Além disso, é também dever de todos respeitar e proteger a dignidade humana, própria e alheia. Logo não se pode falar em dignidade da pessoa humana, concreta, se isso não se materializa em suas próprias condições de vida - deve-se, pois, garantir ao homem o direito de alcançar, mediante o seu trabalho, os recursos indispensáveis para desfrutar de uma vida digna segundo um patamar mínimo civilizatório (BRITO FILHO, 2004).

A concessão do trabalho em condições decentes é uma maneira de proporcionar direitos decorrentes do atributo do trabalho ao homem, cuja tradução é a própria dignidade. Nesse contexto, o Direito do Trabalho consolida-se como o principal instrumento de concretização da dignidade da pessoa humana, ao possibilitar a inclusão efetiva do indivíduo-trabalhador na sociedade capitalista.

Não obstante as diversas inovações laborais e a mutabilidade da própria história dos homens, o que tem revelado grande parte da literatura trabalhista e a vida real é que as relações de trabalho são naturalmente desequilibradas. É cediço que a subordinação do empregado em face de seu empregador, aliada ao trato sucessivo que, a princípio, envolve o liame empregatício, acabam por forjar um ambiente relativamente fértil para situações afrontadoras de direitos fundamentais. Em consequência, descortinado o alto potencial lesivo do poder privado patronal, impõe-se enxergar no contrato de trabalho um campo extremamente propicio à incidência da eficácia horizontal dos direitos fundamentais.

Na constatação da eficácia dos direitos fundamentais também nas relações privadas, como efeito da construção do Estado Social, Sarlet (2005, p. 374) destaca que a liberdade individual "não apenas carece de proteção contra os poderes públicos, mas também contra os 
mais fortes no âmbito da sociedade, isto é, os detentores de poder social e econômico, já que é nesta esfera que as liberdades se encontram particularmente ameaçadas”.

A eficácia horizontal dos direitos fundamentais, que predica a força vinculante e a eficácia imediata dos direitos fundamentais nas relações entre os particulares, sobretudo no que diz respeito às relações privadas em que há nítido desequilíbrio de forças entre os sujeitos envolvidos, fazendo com que os direitos fundamentais exerçam função essencial para o deslinde da questão, é destacada, no Brasil, entre outros, por Sarlet (2007) e Sarmento (2006), a partir da disposição contida no parágrafo $1^{\circ}$ do artigo $5^{\circ}$ da Constituição de 1988 asseguraria a eficácia direta dos direitos fundamentais nas relações jurídicas entre particulares.

Nesse sentido, inclusive, Sarmento (2006, p. 297) destaca que "é possível concluir que, mesmo sem entrar na discussão das teses jurídicas sobre a forma de vinculação dos particulares aos direitos fundamentais, a jurisprudência brasileira vem aplicando diretamente os direitos individuais consagrados na Constituição Federal de 1988 na resolução de litígios privados”.

Ademais, no caput do artigo $7^{\circ}$ da Constituição de 1988 está consagrada importante cláusula de vedação de retrocesso quanto às condições sociais do trabalhador.

Com efeito, a vinculação dos particulares a direitos fundamentais é o liame, a ligação jurídica que alcança não apenas a relação vertical que se forma entre os particulares e o Estado, mas também a relação horizontal entre indivíduos e/ou grupos coletivos, sem que o Estado figure como parte. A compreensão da horizontalidade dos direitos fundamentais representa a compreensão de sua não verticalidade obrigatória e a possibilidade de o aplicador do direito poder manuseá-lo em relações entre entes particulares ou privados.

\section{PRINCÍPIOS DO DIREITO DO TRABALHO E PODER DIRETIVO DO} EMPREGADOR: UMA CONVIVÊNCIA NECESSÁRIA

Toda forma de conhecimento epistemológico necessita basear-se em princípios. Os princípios servem como fundamento lógico de validade para a afirmação das demais asserções que compõem a proposta do saber. Segundo Reale (2012), princípios são verdades fundantes de um sistema de conhecimento.

Os direitos fundamentais caracterizam-se como princípios, considerando-se que, na hipótese de conflito entre eles, deve-se tomar a decisão que não retire a validade de nenhum deles, harmonizando-se o exercício em comum de todos. Os princípios são diversos, mas todos têm o mesmo fundamento - o de originar as regras de conduta - de um povo, visando, Rev. de de Direitos Fundamentais Nas Relações Do Trabalho, Sociais E Empresariais | e-ISSN: 2525-9903 | Goiânia| v. 5 | n. 1 | p. 35-57| Jan/Jun. 2019 
sobretudo, regrar a conduta de forma a propiciar a todos os abrangidos pela conduta uma forma linear de atuação.

Da mesma maneira, os princípios jurídicos são o ponto de partida mais importante do sistema normativo, são verdadeiros alicerces pelo qual se constrói o sistema jurídico. Princípios são valores fundamentais de um sistema através de abstração indutiva. Princípios são valores fundamentais de um sistema jurídico. Têm uma dupla finalidade: hermenêutica (entendimento e aplicação) e integrativa (teleologia ao suprir lacunas de lei).

Na visão de Rodrigues (1978, p. 17) os princípios peculiares do Direito do Trabalho devem cumprir com a suas funções precípuas de cunho interpretativa, informadora e normativa, de modo a favorecer a tutela do trabalhador.

Nesse contexto, o Direito do Trabalho, como instrumento regulatório, historicamente atua na humanização do trabalho, que não pode ser encarado como simples fator de produção - o trabalho não é uma mercadoria, nos termos da Declaração de Filadélfia, de 1944.

O princípio da proteção é considerado fundamental ao Direito do Trabalho, por ser inspirador amplo de todo o complexo de regras, princípios e institutos que compõem toda a estrutura e características próprias desse ramo jurídico especializado (DELGADO, 2013).

Para Rodrigues (1978), o princípio protetor subdivide-se em três outros princípios distintos, quais sejam eles: princípio in dubio pro operario, princípio da prevalência da norma mais favorável ao obreiro e princípio da condição mais benéfica ao trabalhador.

O princípio in dubio pro operário determina que toda vez que estivermos diante de um texto jurídico que traga dúvidas em relação ao seu sentido e alcance, o intérprete deverá buscar aqueles mais favoráveis ao obreiro.

Já o princípio da norma mais favorável orienta que, havendo mais de uma regra de sentido diverso aplicável a determinada situação jurídica, deve-se preferir a que favoreça o obreiro.

Por fim, o princípio da condição mais benéfica orienta que, existindo uma situação já concretamente estabelecida pela norma preexistente, deve prevalecer sobre a que vier a ser criada pela nova norma, desde que a situação anterior já tenha sido reconhecida e se mostre mais favorável ao obreiro.

Além dos princípios supra mencionados e que se relacionam ao estudo proposto, temse o princípio da irrenunciabilidade, que consiste em ser considerado inválido o ato voluntário pelo qual se desligue o empregado de direito reconhecido em seu favor, isto é, ao trabalhador 
não se permite transigir ou transacionar os direitos na circunstância da relação empregatícia (DELGADO, 2013).

Com base nos princípios do direito do trabalho mencionados acima para análise do tema proposto faz-se necessário o estudo do poder diretivo do empregador e seus limites necessários à relação contratual.

Como já exposto, o poder de direção pode ser definido como a faculdade atribuída ao empregador de determinar o modo como a atividade do empregado, em decorrência do contrato de trabalho, deve ser exercida.

Dessa forma, o empregador tem o direito de determinar a estrutura e o funcionamento da empresa, ou seja, a organização empresarial, e também tem o direito de regular as condições da prestação de serviços por parte dos empregados.

O estudo do poder diretivo do empregador constitui um tema de grande importância para o Direito do Trabalho. Em razão da intensidade com que se manifesta no cotidiano das relações individuais de trabalho é que este fenômeno desperta grande interesse da doutrina trabalhista.

O contrato de trabalho se desenvolve em torno de dois sujeitos: o empregador e o empregado e o seu conceito revela a supremacia do empregador e o estado de dependência e pessoalidade do empregado, restrito ao poder diretivo empresarial.

No contrato de trabalho os conceitos de poder e trabalho interagem intensamente. Todavia, não se pode esquecer que, nesse contexto, além do exercício das funções organizadoras, fiscalizadoras e de controle, estão em jogo regras e princípios relativos aos direitos, liberdades e garantias aplicáveis a toda pessoa humana, sendo legítimo ao trabalhador preservá-los e defendê-los frente a abusos do seu empregador.

O empregado, ainda que sujeito ao poder diretivo, atributo indeclinável da empresa, e mesmo estando vinculado ao dever de obediência às ordens que se originam do contrato de trabalho, não está sujeito a um poder patronal absoluto ou ilimitado. Portanto, a incidência dos direitos fundamentais no âmbito do contrato de trabalho se assenta na necessidade de assegurar o respeito à dignidade do trabalhador e estabelecer limites ao exercício do poder diretivo do empregador, para tornar a relação de emprego mais justa e equilibrada.

4 OS DIREITOS FUNDAMENTAIS DO TRABALHADOR COMO LIMITADORES DO PODER DIRETIVO E A APARENTE COLISÃO ENTRE ESTES DIREITOS 
O convívio social do homem, principalmente no ambiente de trabalho, coloca-o sujeito a inúmeras possibilidades de conjunturas agressivas ou ofensivas aos seus direitos de personalidade, garantidos constitucionalmente.

Ocorre que, em algumas situações, a atuação patronal extrapola os limites do razoável ou do necessário ao desenvolvimento das atividades empresariais. Nessa perspectiva, os direitos fundamentais do trabalhador ganham incontestável importância, porquanto atuam como contrapeso ao poder empresarial, limitando a perda das liberdades do empregado e proporcionando a conciliação dos interesses em conflito.

Nesse sentido, Valadares (2009, p. 11) destaca que "Não causa surpresa, de forma alguma, que a gênese e o desenvolvimento mais profundo da teoria Drittwirkung tenha tido como espaço privilegiado o das relações trabalhistas, pois são nestas onde, de forma mais evidente, aparece a função dos direitos fundamentais de neutralizar e compensar posições contratuais assimétricas".

A atividade empresarial como manifestação de livre iniciativa também está sujeita aos limites voltados à tutela da sociedade que não consubstanciados em sua função social, a qual está diretamente ligada à função social da propriedade e à função social do contrato, inclusive no âmbito da relação de emprego. Souza (2008, p. 138) indica a imprescindibilidade de atuação da empresa na valorização do trabalho humano: “A empresa, compreendida como concretização da iniciativa privada, somente receberá tutela jurídica quando atuar em favor de seus empregados, valorizando o trabalho humano".

O trabalho deve ser considerado um elemento essencial à dignidade da pessoa humana, exigindo do empregador a adoção de medidas que coíbam qualquer manifestação de afronta os diretos fundamentais. Destaca-se com precisão a relação entre o valor do trabalho e a dignidade da pessoa humana (MARQUES, 2007, pp. 115-6):

O importante restar aqui, ainda, é quem da forma como foi redigida a Carta de 1988, dando ênfase ao trabalho humano, quer como fundamento da Republica, quer como princípio-base da ordem econômica e da ordem social, não há como interpretar os dispositivos constitucionais com, necessariamente, dar destaque ao trabalho humano, em suas variadas formas, se sobrepondo ele aos demais elementos de dignidade da pessoa humana. Não se pode, com isso, desvalorizar-se e precarizar-se as relações de trabalho, pois isso geraria, por certo, um aumento das desigualdades sociais e prejudicaria a buscas do pleno emprego, marginalizando boa parte da população economicamente ativa. $\mathrm{O}$ que deve ser feito, e isso cabe ou interprete, é que quando este deparar com alguma situação que diga respeito ao trabalho humano, a forma de se resolver o impasse é lavando-se em conta que este mesmo trabalho tem um valor social, que é um elemento da dignidade da pessoa humana, a fim de fazer valores os 
fundamentos e objetivos fundamentais da República (art. $1^{\circ}$ e $3^{\circ}$ ) e os princípios da ordem econômica e social (art. 170 e 193).

Assim, considerando-se que os direitos fundamentais sociais (concernentes ao trabalho) integram o rol de direitos fundamentais, conclui-se que, se não for reconhecido à pessoa humana o direito fundamental ao trabalho digno, está sendo negada a ela a sua própria dignidade (GOLDSCHIMIDT e FERRAZ, 2012).

Porém os direitos não são absolutos. Há, basicamente, duas maneiras de os direitos fundamentais sofrerem restrições, serem relativizados ou limitados. A primeira seria a restrição imposta, em abstrato, pelo legislador ao criar leis restritivas de direitos fundamentais. A segunda se daria via Poder Judiciário, na sentença, de forma concreta, quando há colisão de direitos fundamentais e há que dar prevalência de um direito em detrimento de outro, de acordo com a situação em análise - ainda que harmonizando-os, de forma que um não elimine o outro.

No caso de conflito entre direitos fundamentais, o papel do intérprete é buscar a harmonização prática visando também o princípio da máxima efetividade que deve reger os direitos fundamentais, pois, ainda que a regra seja a de que os direitos não são absolutos, também há que ponderar que os direitos devem gozar da máxima efetividade possível dentro do ordenamento jurídico.

Algumas premissas devem ser seguidas na questão sobre a limitação dos direitos fundamentais. Inicialmente as restrições, quando houver colisão nos casos concretos, deverão ser feitas de acordo com critérios de proporcionalidade para que a ponderação não afete demasiadamente um direito em detrimento de outro, ou seja, ao se partir para a restrição de um direito fundamental, a restrição deverá ser a mínima possível, de forma que um não elimine o outro.

Assim, o princípio de concordância ou da harmonização dos direitos fundamentais implica que nunca se revogará um direito em detrimento de outro; apenas se pode diminuir o âmbito de abrangência (ou incidência) de acordo com o caso concreto. Os direitos fundamentais não se revogam pela colisão em casos concretos ou de aparente conflito, mesmo que um direito não prevaleça num caso concreto não há impedimento para que ele prevaleça em outro caso.

Não existem direitos fundamentais mais importantes, em abstrato, do que outros, tendose por base a premissa de que a Constituição é uma unidade em harmonia e que não há hierarquia entre normas constitucionais. Há que se fazer a verificação de qual situação será mais 
ou menos valorada apenas no caso concreto, na prática, não havendo, pois, como fixar-se de antemão, em abstrato, qual direito irá prevalecer.

Não se ignora o fato de que para o empregador alcançar sucesso na sua produção, necessita ter alguns poderes, inerentes ao próprio contrato de trabalho. Porém, não poderão ser usados de forma discricionária, mas somente para garantir o bom funcionamento da entidade laboral, sob pena de infringir direitos fundamentais do trabalhador. Denota-se que os direitos fundamentais não podem ser utilizados de escudo para a prática de atividades ilícitas e por isso é possível a restrição aos direitos fundamentais caso seja verificada a utilização destes para encobrir atividades ilícitas.

Existem limites ao poder diretivo, não devendo o trabalhador obediência sempre que as ordens ou instruções se mostrem contrárias aos seus direitos e garantias, normalmente quando contrariem algumas das condições previstas na Constituição ou contrárias a regras gerais, como em relação aos direitos de personalidade.

O direito do empregador termina ao iniciar o direito do empregado, ou seja, o empregador poder usar o seu poder de comando, dando ordens ao empregado, desde que não adentre no âmbito dos direitos fundamentais do seu subordinado. Segundo Delgado (1996), no direito subjetivo, a ordem jurídica dá ao seu titular a prerrogativa de agir para satisfação de interesse próprio em estrita conformidade com a norma. Contrapõe-se, assim, a uma obrigação. A ideia de obrigação, embora compreendida na de dever, é mais estrita, importando uma específica determinação de conduta em função de um vínculo formado e de uma contraprestação alcançada na relação concreta. Portanto, direito subjetivo e obrigação são conceitos especificamente delimitados pelo título jurídico que os formulou, não conferindo ao titular a amplitude de ação inerente à ideia de direito protestativo.

Porém a vinculação existente entre os direitos da personalidade e o Direito do Trabalho, cujo objetivo é precipuamente a tutela dos interesses do trabalhador frente ao empregador, assegura um tratamento específico quanto à proteção da personalidade do empregado.

A questão a ser debatida, em síntese, é como compatibilizar o direito do empregador, de dirigir e fiscalizar a prestação pessoal de serviços, inerente ao contrato de trabalho, com a preservação da intimidade do empregado, direito de personalidade de que não se priva aquele que aceita prestar serviços de forma subordinada? O problema suscitado longe está de ser de fácil resolução, dada a relevância e a plasticidade dos valores em conflito.

Desta forma, o princípio da dignidade da pessoa humana cumpre dupla função: serve como importante elemento de proteção dos direitos em face de medidas restritivas e, portanto, 
também contra o uso excessivo dos direitos, bem como justificativa para a imposição de restrições a direitos fundamentais, acabando, nesse sentido, por atuar como elemento limitador destes. Sempre se poderá afirmar que a dignidade da pessoa atua simultaneamente como limite dos direitos e limite dos limites, isto é, barreira última contra a atividade restritiva dos diretos fundamentais, o que efetivamente não afasta a controvérsia sobre o próprio conteúdo da dignidade e a existência, ou não, de uma violação do seu âmbito de proteção (SARLET, 2011).

Percebe-se, nesse contexto, que os direitos fundamentais podem, sim, sofrer restrições, mas desde que respeitados os critérios para diferenciação entre aqueles. A primeira ideia que se deve ter acerca de restrições, para melhor compreender as espécies destas, é aquela alvitrada por Alexy (2001, p. 281):

Uma norma somente pode ser uma restrição a um direito fundamental se ela for compatível com a Constituição. Se ela for inconstitucional, ela até pode ter a natureza de uma intervenção, mas não a de uma restrição. Com isso, fica estabelecida uma primeira característica: normas são restrições a direitos fundamentais somente se forem compatíveis com a Constituição (trad. do a.).

Assim, toda e qualquer restrição a um direito fundamental, para ter validade e legalidade, obrigatoriamente deverá ser compatível com a Constituição. Inúmeras são as espécies de restrições a direitos fundamentais, mas o que se apresenta nesse contexto é que o núcleo das restrições, e, por conseguinte, quais as suas espécies (excerto daquelas que interessam preponderantemente a este trabalho), será melhor compreendido na exegese do termo "compatível com a Constituição".

Compatível com a Constituição é tudo aquilo que não conflitar com esta, que a respeitar, que tenha previsão expressa nela ou ao menos conste autorização para as normas infraconstitucionais realizarem referidas restrições.

Sob este aspecto, as duas espécies de restrições que aqui interessaram preponderantemente são as restrições diretamente constitucionais e as restrições indiretamente constitucionais. As restrições diretamente constitucionais são aquelas de hierarquia constitucional. Assim, quando a Constituição prever um direito fundamental e em seguida uma restrição a ele, estar-se-á diante de uma restrição diretamente constitucional.

A título de exemplo, cita-se o direito fundamental à livre reunião previsto no art. $5^{\circ}$, XVI, da Constituição de 1988. Após garantir este direito, em seguida, o legislador constituinte pode ponderar que haverá restrição àquele direito quando forem usadas armas. Já as restrições indiretamente constitucionais são aquelas que a própria Constituição autoriza alguém 
(infraconstitucionalmente) a estabelecer; sua expressão mais clara se encontra nas cláusulas de reserva explícitas, as quais autorizam expressamente intervenções e restrições.

Nesse ponto, como exemplo de restrição indiretamente constitucional, cita-se o disposto no art. $7^{\circ}$, VI, da Constituição de 1988 , cujo teor garante como um direito fundamental do trabalhador a irredutibilidade salarial. A restrição vem logo após, quando a regra admite que o salário poderá ser reduzido, mediante acordo ou convenção coletiva - ou seja, a própria Constituição consagra um direito fundamental e ao mesmo tempo autoriza o poder infraconstitucional a restringir este direito. Percebe-se que ambas as restrições possuem compatibilidade com a Constituição, estando nela inseridas ou nela autorizadas (GOLDSCHIMIDT e FERRAZ, 2012).

O princípio da dignidade da pessoa humana também serve como justificativa para a imposição de restrições a direitos fundamentais, acabando, neste sentido, por atuar como elemento limitador destes. Como já exposto, sempre se poderá afirmar que a dignidade da pessoa atua simultaneamente como limite dos direitos e limite dos limites, isto é, barreira última contra a atividade restritiva dos diretos fundamentais, o que efetivamente não afasta a controvérsia sobre o próprio conteúdo da dignidade e a existência, ou não, de uma violação do seu âmbito de proteção (SARLET, 2001).

Dessa forma, o princípio da dignidade da pessoa humana cumpre dupla função. Constata-se que o princípio da dignidade da pessoa humana serve como importante elemento de proteção dos direitos em face de medidas restritivas e, portanto, também contra o uso excessivo dos direitos.

Por fim, não se pode desprezar que, apesar, de ser inquestionável que algumas ações empresariais afrontam os direitos fundamentais do empregado, podem essas ações também estar legitimadas pela proteção constitucional, assegurados o direito de propriedade e a livre iniciativa. Em várias situações, pode-se estar diante de um conflito jurídico entre privados onde ambos gozam da proteção dos direitos fundamentais. Por isso, é indispensável que se faça a adaptação dos direitos do trabalhador no plano do contrato de trabalho.

5 O BALANCING TEST COMO TÉCNICA DE PONDERAÇÃO ENTRE O PODER DIRETIVO DO EMPREGADOR E OS DIREITOS FUNDAMENTAIS DE
PERSONALIDADE DO TRABALHADOR 
A técnica de proporcionalidade pode ser desenvolvida de diversas formas. Uma delas é o sopesamento. Contudo, as realidades tanto da ordem jurídica quanto dos conflitos brasileiros destoam de forma discrepante, o que torna a utilização da mesma técnica incompatível.

A utilização da proporcionalidade como "regra de ponderação" entre os direitos em conflitos acentua a existência de outros meios de prova igualmente idôneos e menos invasivos ou constrangedores (MENDES, 2004). Contudo, mister se faz apresentar que a utilização desta técnica oportuniza que os conflitos sejam resolvidos por meio de um equilíbrio entre os interesses conflitantes, buscando definir qual dos interesses - que abstratamente estão no mesmo nível hierárquico legal - tem maior peso no caso concreto.

Nesses casos, o sopesamento passa a ser instrumento de aplicação da maximização dos direitos fundamentais, árdua tarefa diante da complexidade que envolve a necessidade de valoração de interesses, submetendo-se a condição de justificador da teoria dos direitos e garantias fundamentais. Primeiro, por se encontrar espraiado em todo o ordenamento jurídico, onde fundamenta incontáveis formas de limitação de excessos dos três Poderes da República, tanto na Constituição de 1988 como em seus microssistemas; segundo, como dirimente de conflitos entre princípios constitucionais, através do uso de seus três subprincípios.

No entanto, os tribunais pátrios têm se utilizado desta técnica para decidir conforme a consciência, utilizando-se da ponderação como argumento para decidir sem fundamentar. Diante desta realidade, torna-se imprescindível apresentar outras técnicas ponderativas com o intuito de proporcionar o cumprimento da fundamentabilidade das decisões, imposta pela Constituição.

Nesta toada, a técnica de ponderação analisada no presente trabalho é o balancing test, como mecanismo para encontrar uma solução razoável e proporcional quando ocorre uma aparente colisão entre direitos fundamentais.

\subsection{O princípio da proporcionalidade frente os direitos fundamentais de personalidade} do trabalhador

Na relação de emprego, é importante que as partes entendam o limite de seus atos e privilegie a proporcionalidade, adotando formas menos gravosa de atingir o fim pretendido. Quando as partes não são capazes de harmonizar os poderes diretivos e os deveres do empregado de forma a não ferir os direitos do trabalhador, as relações passam a ser litigiosas e a decisão sobre qual direito deve prevalecer se torna dever dos magistrados. 
De acordo com abalizada doutrina do princípio da proporcionalidade, medeia um vínculo de implicação necessária. No campo das relações privadas, no qual se insere o exercício dos poderes diretivos empresariais, para que haja possibilidade de aplicação de critérios da proporcionalidade se torna necessário que o ato empresarial possa afetar, direta ou indiretamente, algum direito do trabalhador que tenha proteção em normas jusfundamentais, porque esses direitos se encontram cercados de uma tutela especial que encontra assento no próprio texto constitucional e nos tratados internacionais sobre direitos humanos, como, por exemplo, as diversas Convenções da OIT.

No âmbito dos direitos fundamentais, a partir da eficácia horizontal dos direitos fundamentais, o poder empresarial e os direitos de personalidade dos trabalhadores tornam possível a violação destes direitos, o que acarreta a aparente colisão entre essas normas. Nessa hipótese, o conflito deve ser resolvido de acordo com o princípio da proporcionalidade, por meio do qual o julgador deve ponderar entre os eventuais direitos ou valores em colisão, por meio de aplicação de critérios científicos para a decisão.

O critério da ponderação conduz a uma exigência de proporcionalidade que implica uma ordem de preferência relativa ao campo concreto e que se caracteriza pelo fato de que por meio dela não se pode alcançar uma resposta válida para todo o suposto do conflito, apenas afirmando qual dos direitos deve prevalecer o caso concreto, tratando-se desse modo, de hierarquia móvel que não condiz com a declaração de invalidade de um dos bens ou valores em conflito, na formulação de um deles como exceção frente a outro, se não na preservação de ambos, porque inevitavelmente ante cada caso de conflito é preciso reconhecer a um ou a outro (LIMA FILHO, 2017).

O princípio da proporcionalidade foi introduzido no direito administrativo no século XIX como princípio geral do direito de polícia. Mais tarde, seria o princípio da proporcionalidade elevado à condição de princípio constitucional (CANOTILHO, 2002). Além disso, a razoabilidade enseja desde logo uma ideia de adequação, idoneidade, equidade, traduz aquilo que não é absurdo, tão somente o que é admissível, além do bom senso, prudência e moderação (BARROS, 2000).

Assevera-se que o princípio tem um sentido amplo e outro mais restrito: de forma mais limitada, passa a ideia de equilíbrio entre duas grandezas, uma relação harmônica; por outro lado, em sentido amplo, a proporcionalidade envolve adequação entre meios e fins, e a utilidade de um ato para a proteção de um determinado direito. Assim, o princípio da proporcionalidade 
se divide em três subprincípios: da adequação, da necessidade e da proporcionalidade em sentido estrito (BARROS, 2000).

De mesma sorte, Meirelles (2004) afirma que o princípio da proporcionalidade também pode ser chamado de proibição do excesso, cujo objetivo é a análise da compatibilidade entre meios e fins, evitando as restrições desnecessárias ou abusivas. Assim, a razoabilidade e a proporcionalidade não podem ser compreendidas de forma separada.

Nas relações de trabalho, indiscutível é que o gozo dos direitos dos trabalhadores encontra-se diariamente em rota de colisão com os poderes empresariais, tornando-se de difícil conciliação, haja vista que a relação de emprego é, na sua essência, uma relação de autoridade. Dessa forma, percebe-se a importância dos direitos de personalidade nas prerrogativas individuais inerentes à pessoa humana do trabalhador. Direitos estes que têm características marcantes e são protegidos de forma salutar pelo texto normativo, não se podendo submeter a renúncia, transação, alienação, penhora, prescrição ou expropriação.

O Código Civil inova e institui capítulo específico para os direitos da personalidade, utilizando-se de conceito aberto, como o faz em diversas outras passagens, de maneira a remeter à doutrina - e à jurisprudência - a construção das situações particulares de definição e defesa de tais interesses. Por serem direitos fundamentais de todos os seres humanos, também se refletem nos trabalhadores, cuja essência não se destoa da atividade profissional.

Assim, relevante suas implicações nas relações de trabalho, nas quais o poder diretivo do empregador coloca-se, claramente, dente os mais importantes efeitos do contrato de trabalho, vez que concentra prerrogativas ao empregador que irão conferir enorme influência no contexto socioeconômico e, naturalmente, na vida do trabalhador, podendo afetar o exercício de parte das suas liberdades.

A proporcionalidade tem um sentido de relação entre duas grandezas que devem ser comparáveis, a permitir uma noção inevitável de equilíbrio. Sempre que houver limitação às normas jusfundamentais, o princípio da proporcionalidade deve ser observado. A concepção da teoria dos limites dos limites possui ligação com o caráter de princípio dos direitos fundamentais, isto é, os princípios, como mandados de otimização, podem ser cumpridos em diferentes graus, em virtude de sua condição prima facie.

E é em virtude de os princípios serem mandados de otimização e não mandados definitivos, que os conflitos entre regras jurídicas serão resolvidos no âmbito da validade, ou seja, a regra válida exclui a outra, o conflito de princípios será resolvido levando em conta seu 
peso. Contudo, para os direitos fundamentais não se pode utilizar a mesma fórmula. Assim, para a solução de conflito de direitos fundamentais, imprescindível é a aplicação da ponderação ou balanceamento dos direitos conflitantes, levando-se em conta as características especiais do caso concreto.

Nessa senda, a colisão não é resolvida em abstrato ou aprioristicamente em favor sempre dos trabalhadores, mas haverá necessidade aplicar a proporcionalidade em cada caso concreto. Quando há vários meios para se realizar um direito, deve-se observar aquele que menor restrição possível cause a direitos e alcance as maiores vantagens, aí este meio é proporcional e o conflito se resolve em favor dele.

A chave para dar segurança jurídica e justificar de modo fundamentado a ponderação é a adoção do princípio da proporcionalidade com suas regras da adequação, da necessidade e a proporcionalidade sentido estrito, como afirma Pulido (2005). No entanto, alguns doutrinadores, conforme Ávila (2008, p. 234), chamam atenção para a falta de cuidado na hermenêutica atual e de técnica quanto à aplicação do princípio da proporcionalidade:

\begin{abstract}
A ausência de adequação e de proporção torna a restrição injustificável diante do princípio da proporcionalidade e permite afirmar que na situação de provas produzidas por particulares, há uma relação de precedência condicionada prima facie do princípio da proteção penal frente $\mathrm{o}$ princípio da inadmissibilidade. Entender de forma diversa implica negligenciar a realidade, a lógica e o senso comum de justiça (ÁVILA, 2008, p. 234).
\end{abstract}

Denota-se que, com relação ao regramento proporcional, além da permissividade de uso pela jurisprudência, verifica-se a importância do tratamento da razoabilidade pelo legislador, como elemento indispensável à feitura da lei.

\title{
5.2 A proporcionalidade como resolução de aparentes conflitos entre direitos
} fundamentais

Quando se trata de conflito entre direitos fundamentais relacionadas à personalidade do indivíduo, deve-se ter especial atenção no definir qual direito prevalece na relação existente, através de ponderação; para essa reflexão acerca dos conflitos de direitos fundamentais, frisase que, em casos em que se tratam direitos fundamentais relacionados à personalidade do indivíduo e a sua coexistência de liberdades subjetivas, deve-se aplicar as diretrizes postas no ordenamento jurídico, buscando compor os interesses para que os indivíduos possam conviver de maneira pacificada em sociedade (CACHAPUZ, 2006).

Além dos benefícios de segurança jurídica que traz a aplicação da proporcionalidade por meio de critérios científicos para decisão, também se verifica um raciocínio mais Rev. de de Direitos Fundamentais Nas Relações Do Trabalho, Sociais E Empresariais | e-ISSN: 2525-9903 | Goiânia| v. 5 | n. 1 | p. 35-57| Jan/Jun. 2019 
transparente dos juízos que abraçam uma ampla gama de razões. Além disso, fornece uma ponte entre a tomada de decisões nos tribunais e tomada de decisão pelo povo, legislaturas e funcionários públicos. Isto porque a doutrina da proporcionalidade indiscutivelmente convida mais participativa deliberação sobre direitos constitucionais e pode atingir a maior conformidade com valores constitucionais, oferecendo uma rubrica para a tomada de decisão que é acessível para esses outros tomadores de decisão.

O balanceamento é o produto de um processo racional de tomada de decisão por atores que possuem tanto as informações necessárias quanto a capacidade para avaliar os possíveis resultados e consequências de suas ações e decisões. Portanto, as pessoas envolvidas no ato de balanceamento devem ser capazes de estimar tanto os benefícios e prejuízos que estão envolvidos e as probabilidades de resultados incertos (GROSS, 2010).

Ainda hoje persiste o entendimento de que o eventual conflito entre regras é resolvido pelo critério da validade, em que uma delas perde por ser declarada inválida. O conflito entre princípios é resolvido de forma diferente. Canotilho (2003, p. 1182) expõe sobre ponderação e peso quando leciona sobre a colisão dos princípios, afirmando que "a pretensão de validade absoluta de certos princípios com sacrifício de outros originaria a criação de princípios reciprocamente incompatíveis, com a consequente destruição da tendencial unidade axiológiconormativa da lei fundamental". Portanto, as supostas colisões, em verdade, são apenas aparentes.

Ou seja, o conflito entre princípios é dirimido pelo exercício da ponderação de bens por meio de critérios racionais - conhecidos pela técnica do balancing test - que deve aquilatar interesses. Isso porque os princípios possuem dimensão distinta das regras, sendo que aquele que irá resolver o conflito deve levar em conta a força de cada um, não se obtendo mensuração exata de que um princípio será frequentemente objeto de controvérsia.

Não sendo dirimidos os conflitos no jogo binário do "tudo ou nada" - como é feito com as regras, onde a validade de uma significa a invalidade de outra, e uma seria excluída de forma absoluta para que a outra tivesse a força exclusiva de norma válida -, os princípios devem ser ponderados por meio da técnica de proporcionalidade para o fim de que seja minimizada a aplicação de um para a garantia da máxima aplicação do outro. Ou seja, um dos princípios deve ser retraído para que o outro seja consequentemente maximizado, o que faz surgir a necessidade de socorro ao princípio da proporcionalidade, por isso também de princípio de otimização. 
Assim, justamente por serem princípios, na hipótese de uma aparente colisão o princípio que não for aplicado ao ato ou fato não será extirpado do ordenamento jurídico. Isso porque essa relação condicionada de precedência faz com que em determinado caso prevaleça um princípio, às vezes o outro, dependendo do caso em análise, mostrando-se útil aqui aquela ideia anteriormente esposada, de que os princípios são mandamentos de otimização, ou seja, uma norma que será realizada na maior medida possível diante das condições fáticas e jurídicas existentes.

Diante do aparente conflito, há que encontrar um meio que permita dirimi-lo, pelo que o confronto de interesses e bens jurídicos requer juízo de solução para concluir qual dos princípios deverá prevalecer e em que medida, sempre com a preocupação quanto ao mínimo de efetividade do outro não otimizado naquele caso concreto, a evitar-lhe o sacrifício total.

Se houver possibilidade da harmonização - convivência pacífica dos dois princípios com o máximo de efetividade -, o caso está solucionado: ambos terão sobrevivência. Mas se um tiver que ser sacrificado, busca-se a solução nos subprincípios do princípio da proporcionalidade - em verdadeiro exercício de interpretação.

A harmonização é fase que tende a preceder o conflito concreto, mas, quando os princípios constitucionais estão eventualmente em efetiva colisão, o princípio da proporcionalidade assume a condição de instrumento de ativação da ponderação, informando pelo balancing test - qual deles deve ser aplicado, maximizando-o, em detrimento do outro que vai ser, para aquele caso específico, minimizado.

Assim, quanto mais próxima for a possibilidade de se fixar o peso de cada direito posto em conflito, maior será a facilidade de solucionar as dúvidas que devem levar à otimização. Eventualmente, pode-se verificar a possibilidade de ocorrer aniquilamento de um direito fundamental quando em conflito real com outro, a exemplo do que ocorre no caso da defesa legítima. Neste caso, uma vida desaparece para que outra se mantenha, desde que ocorra necessidade e moderação na atitude de quem se defende da agressão injusta.

O fundamental, portanto, é compreender que os direitos fundamentais, que são interdependentes entre si, formam parte de um sistema constitucional no qual o mínimo e o máximo definem-se através de uma relação com outros direitos ou bens do próprio sistema. Em qualquer caso, a falta de respeito a esse conteúdo mínimo supõe que o direito resta violado seu exercício, o que pode acabar desvirtuando e a dignidade dos seus destinatários afrontada. 
6 CONSIDERAÇÕES FINAIS: O BALANCING TEST COMO TÉCNICA DE PONDERAÇÃO EM CASOS DE APARENTE COLISÃO ENTRE OS PRINCÍPIOS DO DIREITO DO TRABALHO E PODER DIRETIVO

A necessidade de dirimir conflitos entre direitos vem fazendo emergir a importância do princípio da proporcionalidade na teoria dos direitos e garantias fundamentais. O princípio da proporcionalidade cumpre a função de estruturar o procedimento imperativo para a determinação de conteúdos de direitos fundamentais que resolvam vinculantes para o legislador e para a fundamentação de certo conteúdo das decisões de controle de constitucionalidade das leis (PULIDO, 2005).

O dilema consiste em elucidar se o tribunal dispõe de algum critério para estruturar sua racionalização no espaço correspondente a brecha de deliberação e logo fundamenta sua decisão, ou se, pelo contrário, as decisões que o tribunal adota no âmbito dessa brecha de deliberação são discricionárias, não respondendo a nenhum tipo de regra metodológica e são, portanto, incontroláveis (PULIDO, 2005).

O princípio da proporcionalidade resulta da indispensável construção de um modelo para que esse princípio expresse quais são as condições sob as quais pode obter-se maior racionalidade possível na sua aplicação (PULIDO, 2005). Nossa reconstrução persegue fixar um conjunto de regras argumentativas que expresse de que modo à aplicação deste princípio pode cumprir, em maior medida possível, as exigências de racionalidade que entram em jogo na concretização das disposições fundamentais.

Neste contexto, é preciso verificar se a prevalência de um direito fundamental não sacrifique outro, sendo a ponderação suscetível de alcançar uma justificação constitucional objetiva e razoável. Com a finalidade de verificar se a medida impeditiva do exercício do direito supera o juízo de proporcionalidade exigível, é necessário constatar se cumpre os seguintes requisitos/condições: se a medida é suscetível de conseguir o objetivo proposto; se não existiam outras medidas mais moderadas para a consecução de tal proposito com igual eficácia; e se a medida era proporcional em sentido estrito, ou seja, ponderada e equilibrada se derivam mais benefícios e vantagens para o interesse geral que prejuízos sobre outros bens e valores em conflito.

Outro critério é a adequação, sendo que as regras que podem ser submetidas ao exame de proporcionalidade são aquelas que possuem posição jusfundamentais prima face e tenham superado os exames de idoneidade e necessidade (subprincípios). De acordo com a definição 
anterior, o discurso argumentativo do princípio da proporcionalidade em sentido estrito deve se estruturar em três passos:

1. O primeiro denominado de subprincípio da adequação. consiste em determinar as magnitudes que devem ser ponderadas, é decidir a importância da intervenção ao direito fundamental e a importância da realização do fim perseguido pela intervenção legislativa com a obtenção de um fim constitucionalmente legitimo.

2. O segundo subprincípio da necessidade consiste em comparar essa magnitude, a fim de determinar se a importância da realização do fim perseguido pela intervenção legislativa é maior que a importância da intervenção no direito fundamental.

3. O terceiro é construir uma relação de precedência condicionada entre o direito fundamental e o fim legislativo, com base no resultado da comparação levada a cabo no segundo passo.

A norma legal ou a abstenção não guarda uma relação de causalidade positiva ótima com um direito fundamental e, portanto, deve considerar-se como uma intervenção neste direito, se não conduz a um estado de coisas em que a realização do direito fundamental seja garantida na maior medida possível.

O subprincípio da idoneidade, que busca verificar a adequação, segue as mesmas regras que a proibição do excesso: uma abstenção legislativa ou uma norma legal que não proteja um direito fundamental de maneira ótima, torna vulnerável as exigências do princípio da idoneidade, quando não favorece a realização de um fim legislativo que seja constitucionalmente legítimo.

Sobre o subprincípio da necessidade, uma abstenção legislativa ou uma norma legal que não proteja um direito fundamental de maneira ótima torna vulnerável as exigências do princípio de necessidade, quando existe outra abstenção ou outra medida legal alternativa que favoreça as realizações do fim do parlamento por menos com a mesma intensidade, e favoreça mais a realização do direito fundamental de proteção. Toda medida de intervenção nos direitos fundamentais deve ser a mais benigna para com o direito objeto da intervenção, entre todas aquelas que se revestem, pelo menos, da mesma idoneidade para alcançar o objetivo proposto.

É preciso, portanto, que seja verificada a real indispensabilidade da restrição a ser implementada e se tal restrição é a menos gravosa entre as possíveis (princípio da menor lesão). Deve ser respondida positivamente a seguinte questão: “Este meio é indispensável?" e, negativamente, a seguinte questão: “Não existe outro meio menos gravoso?”. Além disso, só se 
analisa a necessidade após passar pelo filtro da adequação, algo só pode ser necessário se for adequado, porém, nem tudo que é adequado poderá ser necessário.

Sobre o subprincípio da proporcionalidade em sentido estrito: uma abstenção legislativa ou uma norma legal que não proteja um direito fundamental de maneira ótima torna vulnerável a exigência do princípio de proporcionalidade em sentido estrito quando o grau de favorecimento do fim legislativo é interior que o grau que não se realiza direito fundamental de proteção (PULIDO, 2005).

Conforme o princípio da proporcionalidade em sentido estrito, a importância dos objetivos perseguidos por toda intervenção nos direitos fundamentais deve guardar uma adequada relação com o significado do direito sob intervenção. Em outros termos, as vantagens que são obtidas mediante a intervenção no direito fundamental devem compensar os sacrifícios que esta implica para os titulares e para a sociedade em geral. Que impõe ao legislador a verificação da compatibilização entre os resultados alcançados e as restrições impostas, verificando, em caráter pragmático a proporção entre os fins e os meios, entre resultados e objetivos, entre ganho obtido e restrição realizada.

Quando se representa uma colisão entre um direito fundamental de defesa e um direito fundamental de proteção, deve aplicar-se simultaneamente o princípio de proporcionalidade em sua função de proibição de excesso e proibição de proteção. Nesse caso, a falta de realização máxima do direito de proteção só é admissível na medida em que se exija a realização do direito de defesa e, consequentemente, a intervenção no direito de defesa só é admissível na medida em que se exija a realização do direito de proteção. Nessa dupla aplicação do princípio de proporcionalidade também se deve respeitar o âmbito de apreciação empírica e normativa do legislador (PULIDO, 2005).

Em resumo, para verificação da proporcionalidade deve-se: 1) verificar se o meio escolhido é adequado para a realização do fim buscado; 2) se a restrição causada pelo meio é absolutamente necessária para a realização do fim; e 3) se houve ganho grande com o objetivo alcançado que seja proporcional ás desvantagens que causa, isto é proporcionalidade em sentido estrito.

\section{REFERENCIAS}

ALEXY, R. Teoría de los derechos fundamentales. Madrid: CEC, 2001. 
ÁVILA, T. A. Provas ilícitas e proporcionalidade: uma análise da colisão entre os princípios da proteção penal eficiente e da inadmissibilidade das provas obtidas por meios ilícitos. Rio de Janeiro: Lumen Juris, 2008.

BARROS, S. T. O princípio da proporcionalidade e o controle de constitucionalidade das leis restritivas de direitos fundamentais. 2.ed. Brasília: Brasília Jurídica, 2000.

BRITO FILHO, J. C. Trabalho decente: análise jurídica da exploração do trabalho - trabalho forçado e outras formas de trabalho indigno. São Paulo: LTr, 2004.

CACHAPUZ, M. C. Intimidade e vida privada no novo Código Civil brasileiro: uma leitura orientada no discurso jurídico. Porto Alegre: Fabris, 2006.

CANOTILHO, J. J. Direito constitucional e teoria da Constituição. 6.ed. Coimbra: Almedina, 2002.

CANOTILHO, J. J. Direito constitucional. 7.ed. Coimbra: Almedina, 2003.

CORDEIRO, A. M. Manual de direito do trabalho. Coimbra: Almedina, 1994.

DELGADO, M. G. Curso de direito do trabalho. 11.ed. São Paulo: LTr, 2013.

DELGADO, M. G. Princípios de direito individual e coletivo do trabalho. 2.ed. São Paulo: LTr, 2014.

GOLDSCHMIDT, R.; FERRAZ, D. Depressão acometida ao trabalhador agroindustriário: restrição à eficácia do direito fundamental social ao trabalho digno. Revista de Direitos e Garantias

Fundamentais, Vitória, n. 12, jul./dez. 2012.

GROSS, O. The process of balancing. Tulsa Law Review, vol. 45, issue 4, dez. 2010. Disponível em: https://heinonline.org/HOL/Page?public=true \&handle=hein.journals/tlj45\&div=51\&start_page=733\& collection=journals\&set_as_cursor=0\&men_tab=srchresults. Acesso em 02jan.2019.

LIMA FILHO, F. C. Os direitos fundamentais e a boa-fé como limites do poder diretivo empresarial. São Paulo: LTr, 2017.

LUÑO, P. O poder diretivo empresarial e a tutela inibitória dos direitos fundamentais dos trabalhadores. Revista IOB Trabalhista e Previdenciária. Porto Alegre, v. 1, n.1, jul. 1989.

MARQUES, R. S. Valor social do trabalho, na ordem econômica, na Constituição brasileira de 1988. São Paulo: LTr, 2007.

MEIRELLES, H. L. Direito administrativo brasileiro. 29.ed. São Paulo: Malheiros, 2004.

MENDES, G. F. Direitos fundamentais e controle de constitucionalidade. São Paulo: Saraiva, 2004.

MERINO, L. T. et al. O universo dos direitos da personalidade do empregado(a) no contrato de trabalho e o marco constitucional de 1988. Lex Magister, ano 32, n. 379, jul. 2015.

NASCIMENTO, A. M. Curso de direito do trabalho. 23.ed. São Paulo: Saraiva, 2013.

PULIDO, C. B. El principio de proporcionalidade e los derechos fundamentales. Madrid: CEPC, 2005.

REALE, M. Lições preliminares de direito. 27.ed. São Paulo: Saraiva, 2012.

Rodriguez, A. P. Princípios de direito do trabalho. São Paulo: LTr, 1978.

SARLET, I. W. A eficácia dos direitos fundamentais. Porto Alegre: Livraria do Advogado, 2005.

SARLET, I. W. A influência dos direitos fundamentais no direito privado: o caso brasileiro. In: MONTEIRO, A. P. (Org.). Direitos fundamentais e direito privado: uma perspectiva de direito comparado. Coimbra: Almedina, 2007

SARLET, I. W. Dignidade da pessoa e direitos fundamentais na Constituição federal de 1988. Porto Alegre: Livraria do Advogado, 2001.

SARMENTO, D. Direitos fundamentais e relações privadas. Rio de janeiro: Lumen Juris, 2006. 
SCHWARZ, R. G. Curso de iniciação ao direito do trabalho. São Paulo: Elsevier, 2011.

SOUZA, R. T. Função social do contrato de emprego. São Paulo: LTr, 2008.

VALADARES, L. A. O poder diretivo empresarial e a tutela inibitória dos direitos fundamentais dos trabalhadores. Revista IOB Trabalhista e Previdenciária, São Paulo, v. 21, n. 243, set. 2009. 